Koichi Yamaura* and Tian Xia

\title{
Measuring Bilateral Market Power in International Markets of Vertically Differentiated Agricultural Commodities
}

\begin{abstract}
Two features of international markets of agricultural commodities are bilateral market power of exporting and importing countries and the coexistence of non-genetically modified (non-GM) and genetically modified (GM) products. The two features were not taken into account in most extant studies on market power in international agricultural commodity markets. This research develops a bilateral oligopoly model with the interaction between non-GM and GM commodity and conducts an empirical estimation for U.S.-Japan soybean trade. The estimation results show that U.S. exporters and Japanese importers are almost equally sharing the dominance of market power. The analysis in this research provides new measures of market power and improves the understanding on world soybean markets.
\end{abstract}

Keywords: bilateral oligopoly, market power, non-GM soybeans, vertically differentiated products

JEL Classification: Q17, F12, D43

DOI 10.1515/jafio-2013-0020

\section{Introduction}

World agricultural commodity trade flows have changed dramatically during the last decade. On the production side, major agricultural commodity producing countries such as the United States, Brazil, and China started and expanded the production of genetically modified crops. On the consumption side, world demand for agricultural commodities has been increasing significantly, mostly due to higher incomes in developing countries and world population growth. An important issue in world markets of agricultural commodities is market power.

\footnotetext{
*Corresponding author: Koichi Yamaura, International Environmental and Agricultural Science, Tokyo University of Agriculture and Technology, Tokyo, Japan, E-mail: kyamaura@cc.tuat.ac.jp

Tian Xia, Agricultural Economics, Kansas State University, Manhattan, KS, USA, E-mail: tianxia@k-state.edu
}

Market power may exist in these markets due to high market concentration, barriers to entry, product differentiation, or state trading behaviors. The existence and degree of the market power have important implications for world agricultural producers, consumers, and governments.

To examine and measure the degree of market power, two important features of international markets of agricultural commodities need to be taken into account. One feature is that, on either side of a market, exporting or importing, there are usually a few countries that account for the majority of trade flow. ${ }^{1}$ Thus, both exporting and importing countries may have market power to influence the market price. The second feature is that non-GM and GM products co-exist in international markets of some agricultural commodities, such as soybeans. For any type of agricultural commodity, the non-GM commodity and the GM commodity are vertically differentiated in the sense that, if the prices of the two goods are the same, all consumers will generally prefer the non-GM commodity.

The first feature that both exporting and importing countries have market power is an example of bilateral oligopoly (BO). Gabszewicz and Michel (1997) presented a bilateral oligopoly structure as a special case of a complete multilateral oligopoly structure. A single consumption commodity is traded in a commodity money. Sellers have endowments of the consumption commodity and buyers have endowments of the commodity money. Each agent has market power in the market for which her initial endowment of the commodity is positive. The relative price that clears both markets is the ratio of aggregate offers of two commodities. Bloch and Ghosal (1997) analyzed the incentives to form trading groups in a bilateral oligopoly. Only when all agents trade on the same market, the trading structure is strongly stable. Dickson and Hartley (2013) found that, when the number of buyers becomes large, bilateral oligopoly approaches an alternative game of quantity competition, the market

1 For example, in the world soybean market, the United States and Brazil are the major exporting countries and China, European Union, and Japan are the major importing countries. 
share game. Azzam (1996) is one of the few empirical studies using a bilateral oligopoly model to analyze market power in agricultural and food markets. In the study, an empirical bilateral oligopoly model was developed to estimate the relative market power of packers and retailers in the U.S. beef slaughter and retail industries. Maude-Griffin et al. (2004) conducted an empirical analysis based on a bilateral oligopoly framework to measure the market power of health maintenance organizations and employers in the health insurance market.

The second feature is the coexistence of two differentiated products, non-GM and GM products, in international markets of some agricultural commodities. There are two major approaches for estimating market power in markets of differentiated products: one is estimating the residual demand faced by each firm and the other is estimating a demand system (Perloff et al. 2007). Berry, Levinsohn, and Pakes (1995) studied the U.S. automobile industry by using product-level price and quantity data to estimate demand parameters for a class of differentiated products. Their estimates were the sum of individual purchase probabilities, which is equal to the actual market share of new cars. Goldberg (1995), however, used household-level data in the U.S. automobile industry to examine the probability that a household purchases to determine the demand curve faced by firms. Nevo (2001) decomposed estimated price-cost margins into margins due to product differentiation, multiproduct firm pricing, and potential price collusion in the ready-to-eat cereal industry using a mixed logit model. Pinske, Slade, and Brett (2002) examined the retail gasoline market by using an alternative approach. The product differentiation was due to special competition in their study, and a semiparametric approach was used to analyze cross-price response coefficients. Some problems still exist in estimating market power and further research is needed. For example, because of lacking detailed data on costs, researchers have introduced strong assumptions about cost, e.g., constant returns to scale (Perloff et al. 2007).

Numerous studies have estimated the degree of market power in international markets of commodities and other agricultural/food products. ${ }^{2}$ However, the two features of international agricultural commodity markets were in general not taken into account in the extant

2 Carter, MacLarean, and Yilmaz (1999), Yang and Lee (2001), Cho, Jin, and Koo (2002), Reed and Saghaian (2004), Poosiripinyo and Reed (2005), Song (2006), Andersen, Asche, and Roll (2008), Song et al. (2009), Felt, Gervais, and Laure (2010), Mulik and Crespi (2011), and Yamaura (2011) measure the degree of market power in the trade of agricultural and food products. research. First, the potential bilateral market power of exporting and importing countries was not structurally modeled in previous studies on international markets of agricultural commodities. ${ }^{3}$ Second, the interaction between two vertically differentiated goods - non-GM and GM commodity - was ignored in almost all existing analysis. Yamaura (2014) included the interaction between non-GM and GM soybeans in the estimation of market power in U.S.-Japan soybean trade, but the bilateral market power in international soybean markets was not modeled in his analysis. In sum, no existing study has taken both features, the bilateral market power of exporting and importing countries and the interaction between non-GM and GM commodity, together into consideration to examine market power in international markets of agricultural commodities.

Failing to include either or both features can result in incorrect measures of exporters' or importers' market power in international commodity markets and misleading policy and welfare implications (Mulik and Crespi 2011). This paper addresses this gap in the literature by explicitly including both bilateral market power of exporting and importing countries and the interaction between non-GM and GM commodity in an analysis on the market power of exporters and importers in international soybean markets. We first develop a bilateral oligopoly model to incorporate the interaction between nonGM and GM commodity in the analysis. Then, we use the model to conduct an empirical estimation on U.S.-Japan soybean trade.

\section{Bilateral oligopoly model}

Both U.S. exporters and Japanese importers may have market power to influence the soybean prices in the U.S.-Japan soybean trade. In addition, both non-GM and GM soybeans, the two vertically differentiated commodities, are exported from the United States to Japan. Thus, we develop a bilateral oligopoly model with the interaction between non-GM and GM commodity to capture these two features of the international soybean market.

3 Andersen, Asche, and Roll (2008) and Song et al. (2009) tried to use both the residual demand elasticity (RDE) and residual supply elasticity (RSE) model to measure both exporters' and importers' power in the European dried salted cod market and Chinese soybean trade market. One deficiency of these studies using both RDE and RSE together is that they did not provide a theoretical foundation that allows both exporters' and importers' market power to interact in determining the final market equilibrium. 
This model is developed and specified based on the frameworks in previous research on bilateral oligopoly including Azzam (1996), Gabszewicz and Michel (1997), Bloch and Ghosal (1997), Maude-Griffin et al. (2004), and Dickson and Hartley (2013).

Consider the international soybean market with $N$ exporters and $L$ importers. The market inverse demand function is $P^{O}=f\left(Q^{O}\right)$ with $f^{\prime}<0$, where $P^{O}$ and $Q^{O}$ are the price and the trade volume in international non-GM soybean market, respectively, and superscript " $O$ " denotes non-GM commodity. The market inverse supply function is $P^{O}=h\left(Q^{O}\right)$ with $h^{\prime}>0$.

We first derive the price in international soybean market when $N$ exporters have complete dominance over importers in terms of market power. The profit of exporter $n(n=1,2, \ldots, N)$ is

$$
\pi_{n}^{e x}=\left(P^{O}-\zeta \boldsymbol{Y}\right) q_{n}^{e x}=\left[f\left(Q^{O}\right)-\zeta \boldsymbol{Y}\right] q_{n}^{e x},
$$

where $q_{n}^{e x}$ is the export volume of exporter $n, \boldsymbol{Y}$ is a vector of supply shifters of exported soybeans, $\zeta$ is a vector of parameters, $\zeta \boldsymbol{Y}$ is the average cost of exported soybeans, and superscript "ex" denotes exports. Taking the derivative of $\pi_{n}^{e x}$ with respect to $q_{n}^{e x}$ yields exporter $n$ 's the firstorder condition,

$$
\frac{\partial \pi_{n}^{e x}}{\partial q_{n}^{e x}}=P^{O}+\left(\partial f / \partial Q^{O}\right)\left(\partial Q^{O} / \partial q_{n}^{e x}\right) q_{n}^{e x}-\zeta \boldsymbol{Y}=0,
$$

from which we obtain $P^{O}\left[1+\left(\partial f / \partial Q^{O}\right)\left(Q^{O} / P^{O}\right)\right.$ $\left.\left(\partial Q^{O} / \partial q_{n}^{e x}\right)\left(q_{n}^{e x} / Q^{O}\right)\right]-\zeta \boldsymbol{Y}=0$ for $n=1,2, \ldots, N$. Calculating the summation of the conditions of all $N$ exporters and dividing the summation by $N$ yield

$$
\begin{aligned}
& P^{O}\left\{1+\left(\partial f / \partial Q^{O}\right)\left(Q^{O} / P^{O}\right)\right. \\
& \left.\quad\left[\sum_{n=1}^{N}\left(\partial Q^{O} / \partial q_{n}^{e x}\right)\left(q_{n}^{e x} / Q^{O}\right) / N\right]\right\}-\zeta Y=0 \\
& \quad \Rightarrow P^{O}\left[1+\left(v / \varepsilon_{D}\right)\right]=\zeta \boldsymbol{Y},
\end{aligned}
$$

where $\varepsilon_{D}=\frac{1}{\left(\partial f / \partial Q^{0}\right)\left(Q^{0} / P^{0}\right)}$ is the demand elasticity of international soybean market, $v=\sum_{n=1}^{N}\left(\partial Q^{O} / \partial q_{n}^{e x}\right)$ $\left(q_{n}^{e x} / Q^{O}\right) / N$ is the quantity weighted average of exporter-specific conjectural elasticity. We solve the last condition for $P^{O}$ to obtain the equilibrium price when $N$ exporters have complete dominance of market power,

$$
P^{\text {upper }}=\frac{1}{1+\left(v / \varepsilon_{D}\right)} \zeta \boldsymbol{Y}=\eta \boldsymbol{Y},
$$

where $\eta$ is defined as $\eta=\frac{1}{1+\left(v / \varepsilon_{D}\right)} \zeta$ and it is a vector of parameters to be estimated, and superscript "upper" indicates that $P^{u p p e r}$ is the upper limit of price in the international soybean market.
Then we derive the price in international soybean market when $L$ importers have complete dominance over exporters in terms of market power. The profit of importer $l(l=1,2, \ldots, L)$ is

$$
\begin{aligned}
\pi_{l}^{i m} & =\left(P_{r}^{O}-P^{O}\right) q_{l}^{i m}-C_{r}^{O}\left(q_{l}^{i m}\right) \\
& =\left[P_{r}^{O}-h\left(Q^{O}\right)\right] q_{l}^{i m}-C_{r}^{O}\left(q_{l}^{i m}\right)
\end{aligned},
$$

where $q_{l}^{i m}$ is the import volume of importer $l, P_{r}^{O}$ is the retail/wholesale price that importer $l$ can receive from selling the imported soybeans in its own country's market, $C_{r}^{O}\left(q_{l}^{i m}\right)$ is the importer's selling cost of soybeans, superscript "im" denotes imports, and subscript " $r$ " denotes retail/wholesale. Taking the derivative of $\pi_{l}^{i m}$ with respect to $q_{l}^{i m}$ yields importer l's the first-order condition,

$$
\frac{\partial \pi_{l}^{i m}}{\partial q_{l}^{i m}}=P_{r}^{O}-P^{O}-\left(\partial h / \partial Q^{O}\right)\left(\partial Q^{O} / \partial q_{l}^{i m}\right) q_{l}^{i m}-M C_{r}^{O}=0,
$$

where $M C_{r}^{O}=\partial C_{r}^{O} / \partial q_{l}^{i m}$ is the importer's marginal selling cost of imported soybeans. From the first-order condition, we find $P_{r}^{O}-P^{O}\left[1+\left(\partial h / \partial Q^{O}\right)\left(Q^{O} / P^{O}\right)\left(\partial Q^{O} / \partial q_{l}^{i m}\right)\right.$ $\left.\left(q_{l}^{i m} / Q^{O}\right)\right]-M C_{r}^{O}=0$ for $l=1,2, \ldots, L$. Taking the summation of the conditions of all $L$ importers and dividing the summation by $L$ yield

$$
\begin{aligned}
& P_{r}^{O}-P^{O}\left\{1+\left(\partial h / \partial Q^{O}\right)\left(Q^{O} / P^{O}\right)\right. \\
& \left.\quad\left[\sum_{l=1}^{L}\left(\partial Q^{O} / \partial q_{l}^{i m}\right)\left(q_{l}^{i m} / Q^{O}\right) / L\right]\right\}-M C_{r}^{O}=0 \\
& \quad \Rightarrow P^{O}\left[1+\left(\mu / \varepsilon_{S}\right)\right]=P_{r}^{O}-M C_{r}^{O},
\end{aligned}
$$

where $\varepsilon_{S}=\frac{1}{\left(\partial h / \partial Q^{O}\right)\left(Q^{0} / P^{0}\right)}$ is the supply elasticity of international soybean market, $\quad \mu=\sum_{l=1}^{L}\left(\partial Q^{O} / \partial q_{l}^{i m}\right)$ $\left(q_{l}^{i m} / Q^{O}\right) / L$ is the quantity weighted average of importer-specific conjectural elasticity. We solve the last condition for $P^{O}$ to find the equilibrium price when $L$ importers have complete dominance of market power,

$$
P^{\text {lower }}=\frac{1}{1+\left(\mu / \varepsilon_{S}\right)} \boldsymbol{Z}=\lambda \boldsymbol{Z},
$$

where $\boldsymbol{Z}=P_{r}^{O}-M C_{r}^{O}$ is a vector of demand shifters of imported soybeans, $\lambda$ is defined as $\lambda=\frac{1}{1+\left(\mu / \varepsilon_{S}\right)}$ and it is a vector of parameters to be estimated, and superscript "lower" indicates that $P^{\text {lower }}$ is the lower limit of price in the international soybean market.

In a more common bilateral oligopoly market, neither importers nor exporters have complete dominance. Both importers and exporters have some degree of influence on the market price. If the relative dominance of importers over exporters in terms of market power is denoted as $\alpha$, the market equilibrium price of bilateral oligopoly can 
be specified as a weighted average of the lower and upper price limit,

$$
P^{O}=\alpha P^{\text {lower }}+(1-\alpha) P^{\text {upper }}=\alpha(\lambda \boldsymbol{Z})+(1-\alpha)(\eta \mathbf{Y}) .
$$

For the relative dominance in terms of market power, Azzam (1996) used a single parameter $\alpha \in[0,1]$ to represent the degree of dominance of downstream firms (beef retailers) and $1-\alpha$ to represent the degree of dominance of upstream firms (beef packers). Then the parameter $\alpha$ was estimated and the estimates, $\hat{\alpha}$ and $1-\hat{\alpha}$, are used to interpret the relative dominance of retailers and packers. Maude-Griffin et al. (2004) used a function of various factors, $\gamma_{i t}=\exp \left(Z_{i t}^{\prime} \theta\right)$, to represent the degree of dominance of health maintenance organizations (HMOs) in terms of market power and $1-\gamma_{i t}$ to represent the degree of dominance of employers in the health insurance market, where $Z_{i t}$ is a vector of variables affecting the HMOs' and employers' relative dominance such as the local HMO market structure and the administrative cost ratio of HMOs. $\theta$ is a vector of parameter to be estimated. $\gamma_{i t}$ and $1-\gamma_{i t}$ are calculated using the estimates of $\theta$ and the variable values of $Z_{i t}$ to measure the relative dominance of HMOs and employers.

We derive and use a function of various factors (see Appendix for the derivation),

$$
\begin{aligned}
\alpha & =g\left(\boldsymbol{W}^{N}, \boldsymbol{R}^{L}, P^{G M, J P}, P^{G M, U S}\right) \\
& =\frac{1}{1+\exp \left(\delta_{1}+\delta_{2} P^{G M, J P}+\delta_{3} P^{G M, U S}+\phi \boldsymbol{W}^{N}+\tau \boldsymbol{R}^{L}\right)},
\end{aligned}
$$

to represent the degree of dominance of importers and $1-\alpha$ to represent the degree of dominance of exporters, where $\boldsymbol{W}^{N}$ is a vector of the cost shifters for competing soybean exporting countries, $\boldsymbol{R}^{L}$ is a vector of the cost shifters for competing soybean importing countries, $P^{G M, J P}$ and $P^{G M, U S}$ are the prices of the vertically differentiated substitute, GM soybeans, in Japan and the United States, and $\delta_{1}, \delta_{2}, \delta_{3}, \phi, \tau$ are parameters or vectors of parameters to be estimated. The functional form in eq. [2] can guarantee $\alpha \in[0,1]$ but impose no sign constraints on parameters. $\alpha=0$ indicates the complete dominance of exporters and $\alpha=1$ indicates the complete dominance of importers. When $\alpha_{1}<0.5\left(\alpha_{1}>0.5\right)$, importers have less (more) market power than exporters. When importers completely dominate exporters, the equilibrium international soybean price reaches the lower limit of possible price levels. However, if exporters completely dominate importers, the equilibrium international soybean price is the upper limit of possible price levels. The equilibrium soybean price of a bilateral oligopoly market is the weighted average of the lower and upper price limit and the weights are the degrees of dominance of importers and exporters in terms of market power.

We substitute eq. [2] into eq. [1] to obtain the empirical bilateral oligopoly model with the interaction between non-GM and GM soybeans as

$$
\begin{aligned}
& P_{U S, J P}^{O}= \\
& \frac{1}{1+\exp \left(\delta_{1}+\delta_{2} P^{G M, J P}+\delta_{3} P^{G M, U S}+\phi \boldsymbol{W}^{N}+\tau \boldsymbol{R}^{L}\right)}(\lambda Z) \\
& +\frac{\exp \left(\delta_{1}+\delta_{2} P^{G M, J P}+\delta_{3} P^{G M, U S}+\phi \boldsymbol{W}^{N}+\tau \boldsymbol{R}^{L}\right)}{1+\exp \left(\delta_{1}+\delta_{2} P^{G M, J P}+\delta_{3} P^{G M, U S}+\phi \boldsymbol{W}^{N}+\tau \boldsymbol{R}^{L}\right)}(\eta \boldsymbol{Y})+u
\end{aligned},
$$

(Model with Interaction)

where $\boldsymbol{W}^{N}$ is a vector of the cost shifters for competing soybean exporting countries consisting of the exchange rates between Japan and competing exporting countries such as Canada and China, $\boldsymbol{R}^{L}$ is a vector of the cost shifters for competing soybean importing countries consisting of the exchange rates between the United States and competing importing countries such as the EU, China, and South Korea, $\boldsymbol{Z}$ is a vector of demand shifters of the Japanese market consisting of Japanese average income, $\boldsymbol{Y}$ is a vector of supply shifters in the United States including labor cost, energy cost, and the soybean-corn futures price ratio, $\delta_{1}, \delta_{2}, \delta_{3}, \phi, \tau, \lambda$, and $\eta$ are parameters or vectors of parameters, and $u$ is the error term.

For comparison, we also estimate the empirical BO model when the interaction between non-GM and GM soybeans is ignored. Without the interaction term, the relative dominance of importers over exporters changes to

$$
\tilde{\alpha}=\frac{1}{1+\exp \left(\delta_{1}+\phi \boldsymbol{W}^{N}+\tau \boldsymbol{R}^{L}\right)} .
$$

So the empirical bilateral oligopoly model without the interaction between non-GM and GM soybeans is specified as

$$
\begin{aligned}
P_{U S, J P}^{O}= & \frac{1}{1+\exp \left(\delta_{1}+\phi \boldsymbol{W}^{N}+\tau \boldsymbol{R}^{L}\right)}(\lambda Z) \\
& +\frac{\exp \left(\delta_{1}+\phi \boldsymbol{W}^{N}+\tau \boldsymbol{R}^{L}\right)}{1+\exp \left(\delta_{1}+\phi \boldsymbol{W}^{N}+\tau \boldsymbol{R}^{L}\right)}(\eta \boldsymbol{Y})+u \\
& \quad \text { (Model without Interaction). }
\end{aligned}
$$

Equations [3] and [5] specify two versions of the empirical BO model for U.S.-Japan soybean trade. $P_{U S . J P}^{O}$ is the equilibrium price of non-GM soybeans that Japan imports from the United States. In the estimation, the 
data of Japanese non-GM soybean import price is used for $P_{U S . J P}^{O}{ }^{4}$

The parameters of interest are $\alpha, \tilde{\alpha}, \delta_{2}$, and $\delta_{3}$. The values of $\alpha$ and $\tilde{\alpha}$ measure the relative degrees of dominance of Japanese importers vs. U.S. exporters in terms of market power in two versions of the empirical BO model. The magnitudes of $\alpha$ and $\tilde{\alpha}$ can help us understand the nature of competition in U.S.-Japan soybean trade and provide useful insights for industry participants, researchers, and policy makers. The estimates of $\delta_{2}$ and $\delta_{3}$ can show whether the interaction between two vertically differentiated products (non-GM and GM soybeans) should be included in the estimation of the degrees of market power of soybean importers and exporters.

\section{Data}

Weekly data from January 2000 to December 2011 are used in the estimation. The weekly export price data for U.S. GM soybeans were obtained from Chicago Board of Trade (CBOT). The weekly price and quantity of Japanese nonGM soybean imports and the weekly price of Japanese GM soybean imports from the United States were obtained from Tokyo Grain Exchange. Through contacting representatives of Cargill ${ }^{5}$ and Huron Commodities, Inc., ${ }^{6}$ we obtain the data of non-GM soybean premiums paid to U.S. farmers and know that the non-GM soybean premiums are greatly affected by its demand. Thus, we calculate U.S. non-GM soybean prices as the sum of U.S. GM soybean prices from

4 The data of Japanese non-GM soybean import price instead of U.S. non-GM soybean export price is used for $P_{U S . J P}^{O}$ in the estimation of BO model because the data of Japanese non-GM soybean import price is obtained directly from a single source (Tokyo Grain Exchange) while the data of U.S. non-GM export price is obtained indirectly using the sum of U.S. GM soybean price from CBOT and the (high-protein) non-GM soybean premiums from Cargill and Huron Commodities, Inc. So Japanese import price may be a more accurate representation of the equilibrium price $\left(P_{U S . J P}^{O}\right)$ of non-GM soybeans that Japan imports from the United States. When U.S. nonGM soybean export price is used for $P_{U S . J P}^{O}$ in the estimation, the estimation results show that the signs remain the same and the magnitudes and significance levels are similar for most coefficient estimates.

5 Mr. Jeff Duckworth, Cargill, Bloomington, IL. http://www.cargil lag.com.

6 Mr. Jim Traub, Huron Commodities USA, Monticello, IL. http:// www.huron.com/.
CBOT and the (high-protein) non-GM soybean premiums. Since Japanese soybean wholesalers ${ }^{7}$ import non-GM soybeans to make food products such as tofu, miso, and natto (Japan Tofu Association 2014, Japan Natto Cooperative Society Federation 2014, Miso Online 2014), we use the high protein non-GM soybean premium price to calculate U.S. non-GM soybean prices. ${ }^{8}$

We use real export and import prices in the estimation. U.S. non-GM and GM soybean export prices are transformed to the real terms by using the consumer price index (CPI) in Japan. Data on the monthly CPI in Japan were obtained from the portal site of Official Statistics of Japan, e-Stat. Japanese non-GM and GM soybean import prices are converted into real terms by using the producer price index (PPI) in the United States. The data on the monthly PPI in the United States were obtained from the U.S. Bureau of Labor Statistics. ${ }^{9}$

Japanese personal disposable income (PDI) is used as the destination market demand shifters. ${ }^{10}$ Data on the monthly PDI were obtained from e-Stat. The PDI data are converted into real terms by using the CPI in Japan. Weekly exchange rates between Japan and competing exporting countries including Canada and China were obtained from PACIFIC Exchange Rate Service, the University of British Columbia. These exchange rates are

7 Major soybean wholesalers are Marubeni Corporation http://www. marubeni.com/index.html, Mitsui \& CO., LTD. http://www.mitsui. com/jp/en/index.html, and Sojitz Corporation http://www.sojitz. com/en/index.html.

8 Because the GM soybean price from the CBOT is quoted in cents per bushel and the non-GM soybean premiums are quoted in dollars per bushel, we use Metric Conversions ( 1 Metric Ton $=36.7437$ bushels for soybeans) from the Ag Decision Maker at Iowa State University to convert the data from dollar per bushel to dollar per metric ton.

9 The rationale of using real values instead of nominal values in the empirical estimation is that Japan experienced long-time deflation during the time period (2000-2011) of the study. This long-time deflation is unusual compared with the common slight inflation in many other economies. We are concerned that using the nominal values from a long period of deflation in the estimation may distort some coefficient estimates. For comparison, we also estimate the models with the nominal values. When nominal values are used in the BO model estimation, the signs are the same and the magnitudes and significance levels are similar for most coefficient estimates, compared with the results using real values.

10 Mulik and Crespi (2011) used destination countries' wage index, wholesale price index, or producer price index (PPI) as the cost shifters in an RDE model for Indian and Pakistan Basmati rice exports analysis. 
Table 1: Summary statistics of Non-GM soybean analysis.

\begin{tabular}{|c|c|c|c|c|}
\hline Variable & Mean & Std. dev. & Minimum & Maximum \\
\hline$P^{U S}(\mathrm{JPY} / \mathrm{MT})$ & $34,250.94$ & $10,666.21$ & $18,231.49$ & $68,968.43$ \\
\hline$P^{J P}(\mathrm{USD} / \mathrm{MT})$ & 305.6081 & 72.145 & 193.5037 & 534.8425 \\
\hline$P^{G M, U S}$ (JPY/MT) & $29,959.54$ & $9,094.863$ & $17,062.81$ & $62,324.99$ \\
\hline$P^{G M . J P}(\mathrm{USD} / \mathrm{MT})$ & 268.2251 & 52.66697 & 179.6687 & 423.5965 \\
\hline$Q^{n o n-G M}(\mathrm{MT})$ & 17.07659 & 4.886468 & 5.851398 & 33.45151 \\
\hline$E R^{I P, C A}(\mathrm{CAD} / \mathrm{JPY})$ & 0.011653 & 0.001429 & 0.008209 & 0.014318 \\
\hline$E R^{I P, C H}(\mathrm{CHY} / \mathrm{JPY})$ & 0.072154 & 0.005594 & 0.061614 & 0.083787 \\
\hline$E R^{U S, E U}(\mathrm{EUR} / \mathrm{USD})$ & 0.847115 & 0.153871 & 0.629723 & 1.199544 \\
\hline$E R^{U S, C H}(\mathrm{CHY} / \mathrm{USD})$ & 7.681722 & 0.693274 & 6.310741 & 8.280202 \\
\hline$E R^{U S, K O}$ (KOW/USD) & $1,129.104$ & 127.1173 & 906.38 & 1558.1 \\
\hline Income $e^{I P}$ (JPY) & $10,390.1$ & 434.0878 & $9,560.059$ & $11,228.95$ \\
\hline$S C R^{U S}$ & 2.470471 & 0.377396 & 1.719088 & 3.978125 \\
\hline$L C^{U S}$ & 81.2971 & 12.4855 & 95.4444 & 102.4624 \\
\hline$E C^{U S}$ & 129.2759 & 26.7644 & 94.3 & 192.6 \\
\hline TimeTrend & 313 & 180.5662 & 1 & 625 \\
\hline
\end{tabular}

expressed as the number of competing exporting countries' currencies per Japanese yen. ${ }^{11}$

Cho et al. (2002) emphasized the importance of using real exchange rates, while most previous studies used nominal exchange rates in the estimation of RDE and RSE models. In this study, we use real exchange rates, which are obtained by multiplying nominal exchange rates with the ratios of price levels in the two corresponding countries (Krugman and Obstfeld 2002). ${ }^{12}$

We use labor cost and energy cost as the producers' supply shifters. Data on the monthly labor cost were obtained from the OECD iLibrary, and a monthly commodity fuel index was obtained from the International Monetary Fund as the energy cost. The labor cost and energy cost data are converted to the real terms by using the PPI in the United States. We also use the soybeancorn futures price ratio (SCR) that is synthetically generated using soybean and corn futures prices. The SCR is not a tradable futures contract and is being distributed for information purposes only (CME Group). ${ }^{13}$ Data on the SCR were obtained from CBOT. The EU, China, and South Korea are other importing countries of U.S. non-GM

11 For instance, the exchange rate between Japan and Canada on December 30, 2011, is 0.013157 Canadian dollars per Japanese yen. 12 The real exchange rate measures the purchasing power of a currency relative to another, which is known as purchasing power parity (PPP).

13 The November soybean futures over December corn futures is a key index for the present U.S. soybean farmers to help them decide whether they will continue planting soybeans or shift to corn during the next year. soybeans. Weekly exchange rates between the United States and the other destination countries including the EU, China, and South Korea were obtained from the PACIFIC-ERS. These exchange rates are expressed as the number of other destination countries' currency per U.S. dollar. Table 1 shows the summary statistics of quantity, real prices for U.S. non-GM and GM soybean exports and Japanese non-GM and GM soybean imports, demand shifters, supply shifters, and cost shifters.

\section{Estimation results}

We use nonlinear least squares (NLS) method for the estimation of the empirical BO model based on Azzam (1996) and Maude-Griffin, Feldman, and Wholey (2004). In the estimation, we address the autocorrelation issue. The heteroskedastic-consistent (White robust) standard errors are used and reported. We initially included energy costs of the competitors in the estimation, but these variables were eventually dropped from the model based on the significance levels of coefficient estimates and Akaike Information Criterion (AIC). In addition, to check the potential multi-collinearity among exchange rate variables, we used Collin command in STATA to obtain the tolerance and variance inflation factor (VIF) for each exchange rate variable in all empirical models. All tolerance values are much larger than 0.10 and all VIF's are smaller than 10 so that these values suggest that multicollinearity is not a severe concern for the empirical models. 


\section{The model with interaction}

The estimation results of the empirical BO model with the interaction of non-GM and GM soybeans are reported in Table 2. The degrees of dominance $(\alpha$ and $1-\alpha)$ of Japanese importers and U.S. exporters in terms of market power are calculated using the formulae in eq. [2] and their coefficient estimates. ${ }^{14}$ The average values of $\alpha$ and

Table 2: Estimation results of the Bilateral Oligopoly (BO) models.

\begin{tabular}{|c|c|c|}
\hline & Model without Interaction & Model with Interaction \\
\hline$P^{G M, J P}$ & & $\begin{array}{l}-0.0054^{\star \star \star} \\
(0.0010)\end{array}$ \\
\hline$P^{G M, U S}$ & & $\begin{array}{c}-0.0001^{\star} \\
(0.00003)\end{array}$ \\
\hline$E R^{/ P, C A}$ & $\begin{array}{r}148.629 \\
(127.7)\end{array}$ & $\begin{array}{l}-24.1688 \\
(29.4213)\end{array}$ \\
\hline$E R^{/ P, C H}$ & $\begin{array}{l}-21.324 \\
(25.939)\end{array}$ & $\begin{array}{l}-2.3763 \\
(6.0550)\end{array}$ \\
\hline$E R^{U S, E U}$ & $\begin{array}{l}-0.0010 \\
(0.0011)\end{array}$ & $\begin{array}{l}-0.0004^{*} \\
(0.0002)\end{array}$ \\
\hline$E R^{U S, C H}$ & $\begin{array}{r}2.3654 \\
(2.1773)\end{array}$ & $\begin{array}{l}0.6320^{\star \star \star} \\
(0.2286)\end{array}$ \\
\hline$E R^{U S, K O}$ & $\begin{array}{l}1.5301^{\star \star \star} \\
(0.5294)\end{array}$ & $\begin{array}{l}0.2673^{\star \star \star} \\
(0.0855)\end{array}$ \\
\hline Income $e^{J P}$ & $\begin{array}{r}0.0141 \\
(0.0117)\end{array}$ & $\begin{array}{l}0.0206^{\star *} \\
(0.0085)\end{array}$ \\
\hline$S C R^{U S}$ & $\begin{array}{l}2270.65^{\star \star} \\
(1021.7)\end{array}$ & $\begin{array}{r}-861.879 \\
(1050)\end{array}$ \\
\hline$E C^{U S}$ & $\begin{array}{r}68.277 \\
(171)\end{array}$ & $\begin{array}{c}329.058^{\star \star \star} \\
(122.4)\end{array}$ \\
\hline$L C^{U S}$ & $\begin{array}{l}162.138^{\star * *} \\
(62.0611)\end{array}$ & $\begin{array}{r}-10.938 \\
(68.4916)\end{array}$ \\
\hline Constant & $\begin{array}{c}-12.0656^{\star \star} \\
(4.7155)\end{array}$ & $\begin{array}{r}0.2729 \\
(0.8184)\end{array}$ \\
\hline Adjusted $R^{2}$ & 0.9408 & 0.9613 \\
\hline$D W$ & 2.1524 & 2.0409 \\
\hline
\end{tabular}

Note: *, **, and $* \star \star$ indicate coefficient estimates are statistically significant at the $10 \%, 5 \%$, and $1 \%$ level, respectively.

The values in the parenthesis are heteroskedastic consistent standard errors.

14 The formulae, $\quad \alpha=1 /\left[1+\exp \left(0.27-0.005 P^{G M . J P}-0.0001\right.\right.$ $P^{G M, U S}-24.17 E R^{J P, C A}-2.38 E R^{J P, C H}-0.0004 E R^{U S, E U}+0.63 E R^{U S, C H}$ $\left.\left.+0.26 E R^{U S, K O}\right)\right]$, and the mean values of variables are used in the calculation. Six of the eight coefficient estimates used in the calculation are statistically significant while two are insignificant. Using only the significant estimates in the calculation does not lead to much change in the calculated average values of $\alpha$ and $1-\alpha$. When all coefficient estimates are used, the average values of $\alpha$ and $1-\alpha$ are 0.415 and 0.585 , respectively. When only significant coefficient estimates are used, the average values of $\alpha$ and $1-\alpha$ are 0.414 and 0.586 , respectively. $1-\alpha$ are 0.415 and 0.585 , respectively. These results show that U.S. exporters and Japanese importers have almost equal market power in international soybean markets with a slight U.S. dominance. It is usually believed that U.S. soybean exporters may have strong market power while Japanese importers have little influence on price due to the significant share of U.S. soybeans in Japanese import market. ${ }^{15}$ The estimation results in this study show that taking the two features, bilateral market power and the interaction between non-GM and GM commodity, into account can provide a new measure, the relative dominance in terms of market power of importers and exporters, to examine the market competition in international markets of agricultural commodities.

The coefficient estimates $\left(\hat{\delta}_{2}\right.$ and $\left.\hat{\delta}_{3}\right)$ of the Japanese and U.S. GM soybean price are significant at the $1 \%$ and $10 \%$ level, respectively. ${ }^{16}$ These results indicate that the model with the interaction between non-GM and GM soybeans is preferred.

\section{The model without interaction}

For comparison, we also estimated the empirical BO model without the interaction between non-GM and GM soybeans and its results are included in Table 2. The model's coefficient estimates and the formulae in eq. [4] are used to calculate the degrees of dominance $(\tilde{\alpha}$ and $1-\tilde{\alpha})$ of Japanese importers and U.S. exporters in terms of market power. The average values of $\tilde{\alpha}$ and $1-\tilde{\alpha}$ are 0.359 and 0.641 , respectively. These values indicate that U.S. exporters have significantly more market power than Japanese importers in international soybean market. The comparison of these values with the estimates of $\alpha$ and

15 Using estimates of residual demand and supply elasticities, Yamaura (2011) found that U.S. non-GM soybean exporters' market margin is $22 \%$ and Japanese importers' market margin is only $4 \%$. Nakajima (2013) showed that U.S. exporters' market margin is $10.1 \%$ in U.S.-Japan soybean trade.

16 The signs of $\hat{\delta}_{2}$ and $\hat{\delta}_{3}$ depend on several factors including the interaction/coordination between U.S. exporters' selling strategy for non-GM soybeans and that for GM soybeans, and the substitutability (or complementary) between non-GM and GM soybeans for the demand by Japanese importers and consumers. U.S. exporters' selling strategies for two vertically differentiated products, non-GM and GM soybeans, can result in either a positive or negative relationship between the prices of the two products, depending on the quality and cost difference between the two products, the distribution of consumer preferences, etc. The substitutability (complementary) between two products in consumption can lead to a positive (negative) relationship between the two prices. The signs of $\hat{\delta}_{2}$ and $\hat{\delta}_{3}$ will depend on the nature and relative magnitudes of these effects. 
$1-\alpha$ in the model with the interaction shows that failing to include the interaction between non-GM and GM soybeans leads to overestimated U.S. non-GM soybean exporters' market power and underestimated Japanese importers' market power.

\section{Conclusions}

In this research, a bilateral oligopoly (BO) model is developed and the corresponding empirical estimation is conducted for U.S.-Japan soybean trade. The interaction between non-GM and GM soybeans is included in the BO model. Thus, this study takes two features, bilateral market power of exporters and importers and the coexistence of non-GM and GM commodity, of U.S.-Japan soybean trade into account to improve the measurements of market power of U.S. exporters and Japanese importers.

The estimation results show that U.S. exporters and Japanese importers are almost equally sharing the market power with a slight U.S. dominance. Taking the two features, bilateral market power and the interaction between non-GM and GM commodity, into account provides a new measure, the relative dominance of U.S. exporters and Japanese importers in terms of market power, to evaluate the market competition in U.S.Japan soybean trade. The statistical significances of the coefficient estimates of the interaction terms, Japanese and U.S. GM soybean price, suggest that the inclusion of the interaction between non-GM and GM soybeans is necessary and preferred.

This research can be useful for industry participants in international soybean markets, academic researchers, and policy makers. With the decreasing non-GM soybean production in the United States, Japanese non-GM soybean importers have to pay higher premiums for U.S. non-GM soybeans. Given the significant share of U.S. soybeans in the Japanese import market, it is usually believed that U.S. non-GM soybean exporters could influence the market price while Japanese non-GM soybean importers were just price takers. However, our results indicate that U.S. exporters and Japanese importers are almost equally sharing the dominance in terms of market power in U.S.-Japan soybean trade.

Since the beginning of this century, other large agricultural exporting countries such as Brazil and Argentina have become increasingly stronger competitors to the United States in international markets of agricultural commodities (Yang and Lee 2001; Poosiripinyo and
Reed 2005; Song et al. 2009; Felt et al. 2010). Better policies based on new and improved research are needed to assist agricultural producers and exporters in the United States. Our new estimation results for international soybean markets can be helpful to policy makers in the United States, Japan, and other major agricultural exporting and importing countries. Our results of almost equally shared market power between U.S. exporters and Japanese importers, and the effect of the interaction between non-GM and GM soybeans can be used by policy makers in the design and implementation of policies for the soybean industry. Given that U.S. exporters and Japanese importers share the market power, Japanese policy makers know that the import price their importers pay is not too much higher than the competitive level so that they can adjust their policies and support for domestic soybean producers and consumers accordingly. U.S. soybean exporters do not have much market power as usually expected in U.S.-Japan trade. So U.S. policy makers may reconsider the support level for U.S. soybean producers and exporters. The effect of the interaction between non-GM and GM soybeans in market competition can cause policy makers to make further efforts to coordinate their policies for the industries and markets of non-GM and GM commodities. In addition, the empirical models and estimation results can provide some references for academic researchers analyzing competition issues in international agricultural commodity markets with bilateral market power and differentiated products.

\section{Appendix: Derivation of the degree of dominance ( $\alpha$ and $1-\alpha$ ) of importers and exporters in terms of market power}

The degrees ( $\alpha$ and $1-\alpha$ ) of dominance of importers and exporters depend on the factors that affect the relative market power of importers and exporters. For importers, the cost shifters for competing soybean importing countries can influence their market power in international markets. The market power of exporters will be affected by the cost shifters for competing soybean exporting countries. In addition, the prices of the vertically differentiated substitute, GM soybeans, will impact the relative market power of importers and exporters. Thus, we specify the degrees $(\alpha$ and $1-\alpha)$ of dominance of importers and exporters as functions of these factors, 


$$
\begin{gathered}
\alpha=g\left(\boldsymbol{W}^{N}, \boldsymbol{R}^{L}, P^{G M, J P}, P^{G M, U S}\right) \quad \text { and } \\
1-\alpha=1-g\left(\boldsymbol{W}^{N}, \boldsymbol{R}^{L}, P^{G M, J P}, P^{G M, U S}\right)
\end{gathered}
$$

where $\boldsymbol{W}^{N}$ is a vector of the cost shifters for competing soybean exporting countries, $\boldsymbol{R}^{L}$ is a vector of the cost shifters for competing soybean importing countries, $P^{G M, J P}$ and $P^{G M, U S}$ are the prices of the vertically differentiated substitute, GM soybeans, in Japan and the United States.

In addition, the functional forms used for $\alpha$ and $1-\alpha$ need to guarantee $\alpha \in[0,1]$ but impose no sign constraints on parameters so that we can allow the flexibility for data to find the sign, magnitude, and significance of the effect of each factor. The functional form, $\frac{1}{1+\exp (\gamma \boldsymbol{X})}$, can keep its value in the range of $[0,1]$ and do not impose sign constraints on the coefficient $(\gamma)$ of its argument $(\boldsymbol{X})$, so that we set the degree of dominance as

$$
\begin{gathered}
\alpha=g\left(\boldsymbol{W}^{N}, \boldsymbol{R}^{L}, P^{G M, J P}, P^{G M, U S}\right) \\
=\frac{1}{1+\exp \left[\Phi\left(\boldsymbol{W}^{N}, \boldsymbol{R}^{L}, P^{G M, J P}, P^{G M, U S}\right)\right]} \text { and } \\
1-\alpha=1-g\left(\boldsymbol{W}^{N}, \boldsymbol{R}^{L}, P^{G M, J P}, P^{G M, U S}\right) \\
=\frac{\exp \left[\Phi\left(\boldsymbol{W}^{N}, \boldsymbol{R}^{L}, P^{G M, J P}, P^{G M, U S}\right)\right]}{1+\exp \left[\Phi\left(\boldsymbol{W}^{N}, \boldsymbol{R}^{L}, P^{G M, J P}, P^{G M, U S}\right)\right]} .
\end{gathered}
$$

Then we use a linear functional form for $\Phi\left(\boldsymbol{W}^{N}\right.$, $\left.\boldsymbol{R}^{L}, P^{G M, J P}, P^{G M, U S}\right)$ in order to avoid too complicated final empirical specification for the econometric model. So we have

$$
\begin{aligned}
& \Phi\left(\boldsymbol{W}^{N}, \boldsymbol{R}^{L}, P^{G M, J P}, P^{G M, U S}\right)=\delta_{1}+\delta_{2} P^{G M, J P} \\
& +\delta_{3} P^{G M, U S}+\phi \boldsymbol{W}^{N}+\tau \boldsymbol{R}^{L}
\end{aligned}
$$

where $\delta_{1}, \delta_{2}, \delta_{3}, \phi, \tau$ are parameters or vectors of parameters to be estimated. We substitute [8] into [6] and [7] to obtain the specifications for the degrees of dominance of importers and exporters,

$$
\begin{aligned}
& \alpha=g\left(\boldsymbol{W}^{N}, \boldsymbol{R}^{L}, P^{G M, J P}, P^{G M, U S}\right) \\
& =\frac{1}{1+\exp \left(\delta_{1}+\delta_{2} P^{G M, J P}+\delta_{3} P^{G M, U S}+\phi \boldsymbol{W}^{N}+\tau \boldsymbol{R}^{L}\right)} \text { and } \\
& 1-\alpha=1-g\left(\boldsymbol{W}^{N}, \boldsymbol{R}^{L}, P^{G M, J P}, P^{G M, U S}\right) \\
& \quad=\frac{\exp \left(\delta_{1}+\delta_{2} P^{G M, J P}+\delta_{3} P^{G M, U S}+\phi \boldsymbol{W}^{N}+\tau \boldsymbol{R}^{L}\right)}{1+\exp \left(\delta_{1}+\delta_{2} P^{G M, J P}+\delta_{3} P^{G M, U S}+\phi \boldsymbol{W}^{N}+\tau \boldsymbol{R}^{L}\right)} .
\end{aligned}
$$

The function forms in [9] and [10] can guarantee $\alpha \in[0,1]$ but impose no sign constraints on parameters.

\section{References}

Andersen, T. B., F. Asche, and K. H. Roll. 2008. "Oligopoly and Oligopsony Power in Concentrated Supply Chains." ISIAC Working Paper 08-1. University of Rhode Island.

Azzam, A. M. 1996. "Estimating the Degree of Dominance in a Bilateral Oligopoly." Applied Economics Letters 3:209-11.

Berry, S., J. Levinsohn, and A. Pakes. 1995. "Automobile Prices in Market Equilibrium." Econometrica 63:841-90.

Bloch, F., and S. Ghosal. 1997. "Stable Trading Structures in Bilateral Oligopolies." Journal of Economics Theory 74: 368-84.

Carter, C. A., D. MacLarean, and A. Yilmaz. 1999. "How Competitive is the World Wheat Market." Working Paper No. 99-002, Department of Agricultural and Resource Economics, University of California, Davis.

Cho, G., H. J. Jin, and W. W. Koo. 2002. "Measuring the Market Power of the U.S. Wheat Exporters in Asian countries: An Issue about Adjustment of Nominal Exchange Rate When Using as A Cost Shifter." Paper presented at the American Agricultural Economics Association conference, Long Beach, CA, 28-31 July.

Dickson, A., and R. Hartley. 2013. "Bilateral Oligopoly and Quantity Competition." Economic Theory 52:979-1004.

Felt, M. H., J. P. Gervais, and B. Laure. 2010. "Market Power and Import Bans: The Case of Japanese Pork Imports." Agribusiness 26:1-18.

Gabszewicz, J. J., and P. Michel. 1997. "Oligopoly Equilibrium in Exchange Economies." In Trade, Technology and Economics: Essays in Honor of Richard G. Lipsey, edited by Easton, B. C. and R. G. Harris,217-40. Cheltenham: Elgar.

Goldberg, P. K. 1995. "Product Differentiation and Oligopoly in International Markets: The Case of the U.S. Automobile Industry." Econometrica 63:891-951.

Japan Natto Cooperative Society Federation. 2014. Available at: http://www.710.or.jp/english/index.html

Japan Tofu Association. 2014. Available at: http://www.tofu-as.jp/ english/index.html

Krugman, P., and M. Obstfeld. 2002. International Economics: Theory and Policy, 6th. ed. Boston, MA: Addison Wesley.

Maude-Griffin, R., R. Feldman, and D. Wholey. 2004. "Nash Bargaining Model of $\mathrm{HMO}$ Premiums." Applied Economics 36:1329-36.

Miso Online 2014. Available at: http://www.miso.or.jp/ (in Japanese).

Mulik, K., and J. M. Crespi. 2011. "Geographical Indications and the Trade Related Intellectual Property Rights Agreement (TRIPS): A Case Study of Basmati Rice Exports." Journal of Agricultural \& Food Industrial Organization 9(4):1-19.

Nakajima, T. 2013. "Price Transmission and Market Power in the International Vegetable Oil Markets." PhD dissertation, University of Tokyo.

Nevo, A. 2001. "Measuring Market Power in the Ready-to-Eat Cereal Industry." Econometrica 69:307-42.

Perloff, J. M., L. S. Karp, and A. Golan. 2007. Estimating Market Power and Strategies. Cambridge: Cambridge University Press.

Pinske, J., M. E. Slade, and C. Brett. 2002. "Spatial Price Competition: A Semiparametric Approach." Econometrica 70:1111-53. 
Poosiripinyo, R., and M. Reed. 2005. "Measuring Market Power in the Japanese Chicken Meat Market." Journal of International Agricultural Trade and Development 1:135-48.

Reed, M. R., and H. S. Saghaian. 2004. "Measuring the Intensity of Competition in the Japanese Beef Market." Journal of Agricultural and Applied Economics 34(1):113-21.

Song, B. 2006. "Market Power and Competitive Analysis of China's Soybean Import Market." PhD dissertation, University of Kentucky.

Song, B., M. A. Marchant, M. R. Reed, and S. Xu. 2009. "Competitive Analysis and Market Power of China's Soybean Import Market." International Food and Agribusiness Management Review 12(1):21-42.
Yamaura, K. 2011. "Market Power of the Japanese Non-GM Soybean Import Market: The U.S. Exporters Vs. Japanese Importers." Asian Journal of Agriculture and Rural Development 1(2): 80-89.

Yamaura, K. 2014. "Market Power of the Japanese Soybean Import Market: GMO, Non-GMO, and Vertically Differentiated Products." Japanese Journal of Rural Economics Special Issue (Nihon Nogyo Keizai Gakkai Ronbun-shu 2013) 16: 113-17.

Yang, S. R., and W. J. Lee. 2001. "Exporters' Market Power in Agricultural Import Markets in Korea." In Paper presented at the American Agricultural Economics Association annual meeting, Chicago, IL, 5-8 August. 